\title{
MORPHOLOGIC CHANGES IN THE NODULAR GOITRE INDUCED BY THE LIGASURE HIGH FREQUENCY CURRENT GENERATOR
}

\author{
Tetyana Yermakova
}

\author{
Department of Surgery no 2 of State Higher Education Institution \\ I.Ya. Horbachevsky Ternopil State Medical University, Ministry of Public Health, Ukraine
}

Yermakova T. (2015), Morphologic changes in the nodular goitre induced by the LigaSure high frequency current generator. Health Problems of Civilization, 3 (9), p. 20-23.

\begin{abstract}
Summary: Today, surgical dissection and tissue coagulation with both monopolar and bipolar coagulation as well as LigaSure high frequency current generator (HFCG) are the surgical modalities of choice in the treatment of thyroid pathology. However, the question of the high frequency current effect on the morphofunctional condition of the posthemithyroidectomic parenchyma is still disputable.

The goal of the research is a thorough histological analysis of the surgically removed thyroid tissue specimen.

The nodular goitre of 50 patients was subject to the histological study. The surgery was performed with the LigaSure HFCG. The 1.0x0.5 thyroid tissue specimens were excised from three areas.

Hemithyroidectomy lasted for 40-50 min and thyroidectomy - 120 $\pm 4.2 \mathrm{~min}$. In both procedures, the blood loss was within 70-150 ml, no haemorrhage being observed in both intra-and postoperative period.

The zonal effect of high frequency current on the thyroid structure was determined morphologically, namely coagulation necrosis in the site of direct action, intensified secretory response of the thyroid tissue to the extremal factor in the perifocal area, and typical structure of the nodular goitre with the signs of impaired microcirculation in the remote area.

Morphologic changes of the thyroid gland, with high frequency current used as a dissector, are distance-dependent.
\end{abstract}

Keywords: nodular goitre, thyroid gland, LigaSure

\section{Introduction}

Nodular goitre is prevalent thyroid pathology, the morbidity being estimated today as 30-40 cases per 100 000 population. Of them, 70 per cent are diagnosed as benign and 10 per cent - as malignant (Witzel 2007, Chaudhary et al. 2006). Both conservative and surgical methods of the treatment are used, the postoperative complication rate ranging from 2.5 to 5.0 per cent (10-th World Congress of Endoscopic Surgery 2006, Sadler 2006). This is mostly due to imperfect haemostasis as well as the damage to adjacent organs, firstly the nerves. Wide application of the latest techniques provided notable decrease of both intra-and postoperative complication rate (Vassilios et al. 2005, Shen et al. 2005, Rosato et al. 2004). Today, surgical dissection and tissue coagulation with monopolar and bipolar coagulation as well as LigaSure high frequency current generator (HFCG) are the surgical modalities of choice (Andreas 2004, Foster 1978, Dionigi et al. 2006). However, these methods are not free from shortcomings, in particular with regard to the damaging effect on the surrounding tissues and homeostasis areas, thus conditioning the need of morphologic substantiation of their application in thyroid surgery. The effect of high frequency current on the morphofunctional condition of the post-hemithyroidectomic parenchyma is an open-ended question. Besides, the nature of pathologic process can be mostly determined on the basis of a thorough histological study of the dissected tissue, and it should be taken into account that high frequency current can alter its manifestations. The above-mentioned unclear morphologic aspects of the high frequency current coagulative effect on the thyroid necessitated this study.

\footnotetext{
Address for correspondence: Tetyana Yermakova, I.Ya. Horbachevsky Ternopil State Medical University, m.Voli, 1, Ternopil, 46001, e-mail: tetjana1984@yahoo.com, phone: +380977201388

Tables: 0 Figures: 3 References: 10 Full-text PDF www.hpc.edu.pl Copyright @ Pope John Paul II State School of Higher Education in Biała Podlaska, Sidorska 95/97, 21-500 Biała Podlaska Indexation: Index Copernicus, AGRO, ProQuest, Polish Medical Bibliography, Polish Ministry of Science and Higher Education. This is an open-access article distributed under the terms of the Creative Common Attribution Non-commercial license (http://creativecommons.org/licenses/by-nc/3.0), which permits use, distribution and reproduction in any medium, provided the original works is properly cited, the use is non-commercial and is otherwise in compliance with the license.
} 


\section{Materials and methods of investigation}

Surgically excised thyroid or its lobe was used for the morphological analysis. The surgical intervention was performed on 50 patients (their mean age being 45 years) with the nodular goitre under general anaesthesia and artificial pulmonary ventilation with myorelaxants, by using LigaSure HFCG. The thyroid tissue was fixed in $10 \%$ neutral formalin solution and then studied both macro-and microscopically in accordance with the Agreement on theoretical and practical co-operation between the State Higher Education Institution "I.Y. Horbachevsky Ternopil State Medical University" and Ternopil regional pathologicoanatomic bureau. The 1.0x0.5 thyroid tissue specimens were excised from three areas: first - at the site of high frequency current application; second - in the perifocal area, $0.5 \mathrm{~cm}$ from the electric coagulation site; third $-1.0-2.0 \mathrm{~cm}$ from the electric coagulation site. Dewaxed slices were stained with haematoxylin and eosin as well as with Hart and Malory fuxelin. Histological specimens were analyzed with the use of SEOSCAN and Lumam P-8 microscopes at various magnifications. To obtain documentary photographs, microscope images were taken to the computer monitor with the VISION Color CCD Camera and the Inter video WinDVR.

\section{Results and discussion}

Hemithyroidectomy procedure lasted for 40-50 min and thyroidectomy - $120 \pm 4.2 \mathrm{~min}$. In both procedures, the blood loss was within 70-150 ml, no haemorrhage being observed in both intra-and postoperative period.

Histological study revealed local coagulation necrosis at the site of LigaSure high frequency current application that was confirmed by folliculi outlines with unstained structures, soaked in patches with haemoly tic erythrocytes (Fig.1). Both thyrocytes' cytoplasm and intercellular tissue were eosinophilic, the nuclei poorly defined.

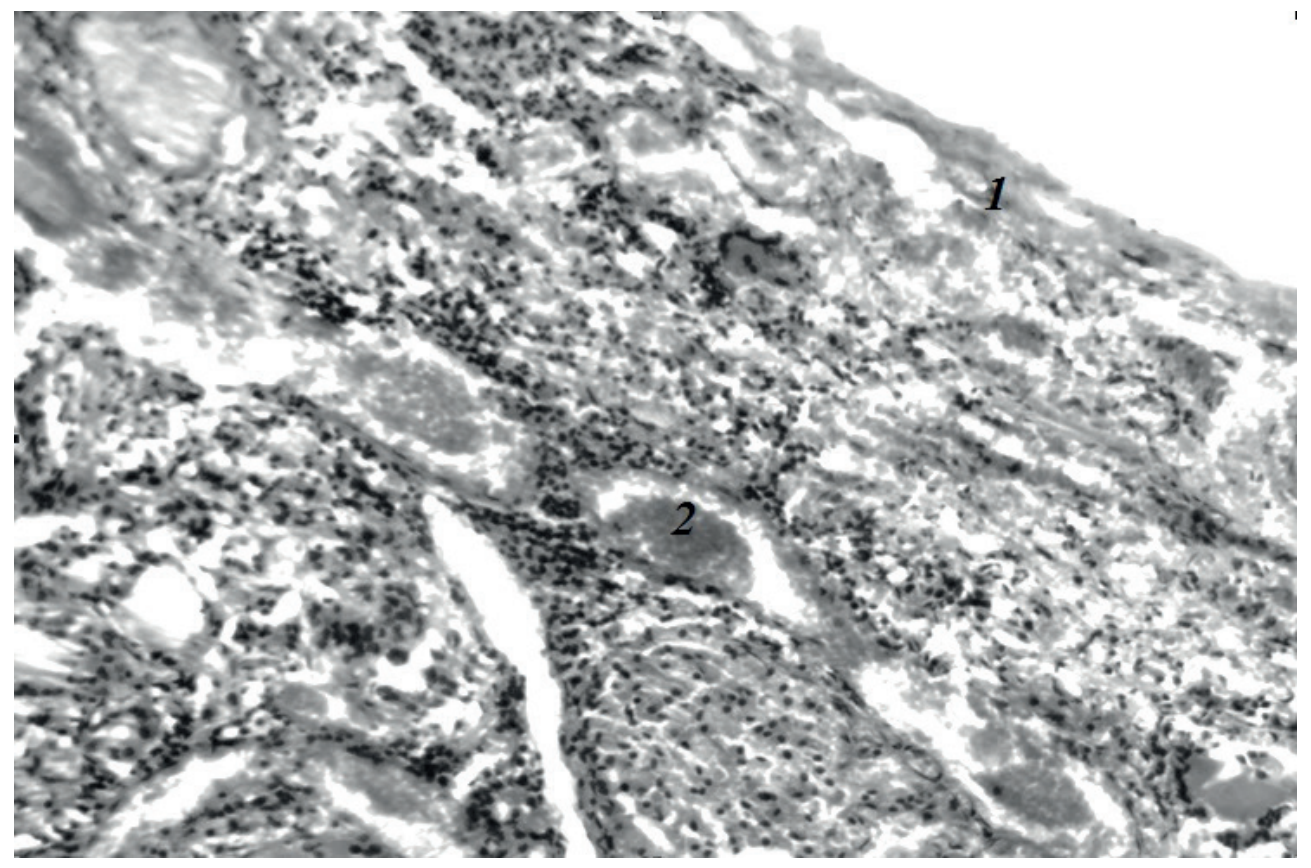

Figure 1. Coagulation necrosis in the area of high frequency current action (1).

Capillary plethora (2). Staining with haematoxylin and eosin. X 80.

Despite the short-term effect of high frequency current, adaptive processes at the background of marked microcirculation disorders were found. Thyrocytes changes revealed themselves in necrotic and dystrophic processes in the form of cytoplasm swelling and clearing, nuclear pyknosis, desquamation of thyroid epithelium into folliculi lumen as well as impaired colloid eosinophilia and basophilia, together with increased number of microvesicles on the epithelium surface. (Fig.2) 


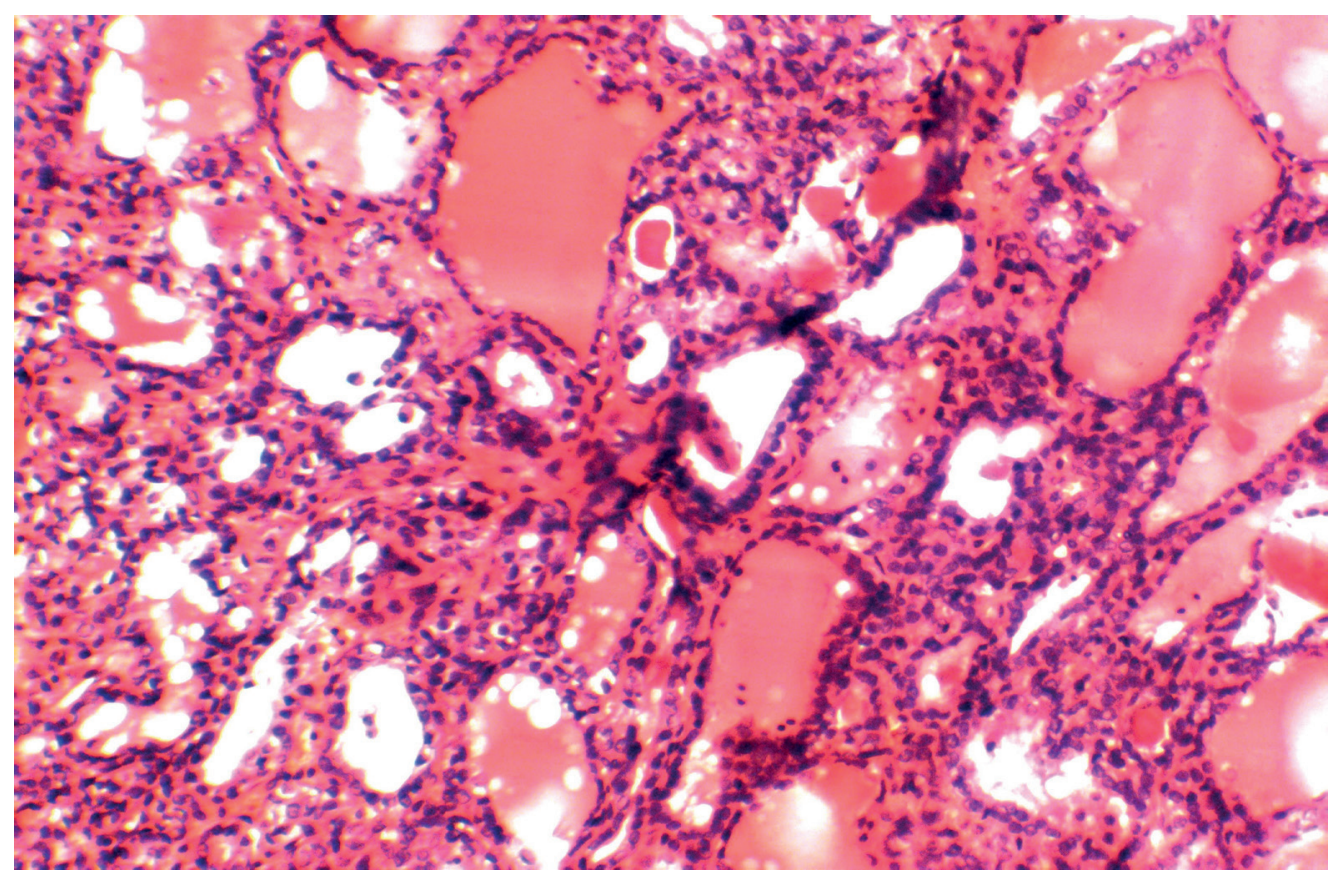

Figure 2. Increased thyroid tissue secretory activity. Staining with haematoxylin and eosin. X 80.

These changes can be reasonably regarded as "emergency" response of the thyroid secretory function to the effect of high frequency current. The current action reveals itself in partial changing of thyrocyte folliculi nuclei, vascular myocytes and stroma. They become oblong-shaped and are intensively stained with haematoxylin.

Microcirculation disorders were non-specific and revealed themselves in differing degree of shock organ reorganization, namely stromal oedema, acute capillary plethora, diapedetic haemorrhages and colloidorrhagias. In most segmental arteries, the subendothelial interlayer is thickened owing to plasmatic impregnation and erythrodiapedesis, the inner elastic membrane having the signs of breakdown and fragmentation. In addition to plethora, red thrombi and plasma coagulants are found in the vascular lumen. Changes of the nodular goitre chronic manifestations were detected in the areas remote from coagulation necrosis. The thyroid parenchyma is characterized by the clusters of large and small folliculi separated by the interlayers of connective tissue. The stroma enlargement is of diffuse type, occupying large area in patches with "immured" thick-walled vessels. (Fig.3).

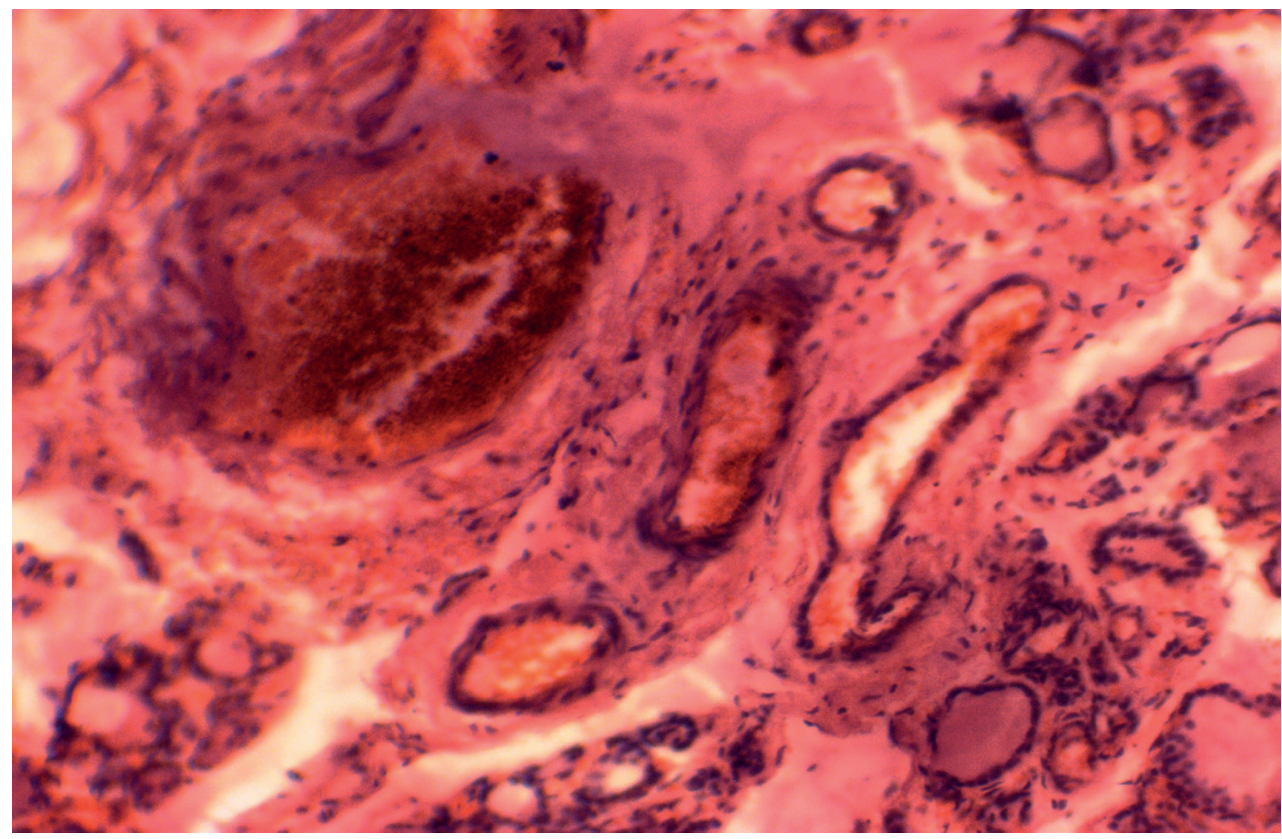

Figure 3. Connective tissue oedema. Vascular thrombosis. Staining with haematoxylin and eosin. X 80. 
In these vessels, endotheliocytes swelling and desquamation as well as dissection of myocytes with plasmorrhagia and perivascular haemorrhages occur. Thrombi appear in the lumen alongside with plethora. These changes are likely to be the manifestations of the bloodstream shock reaction to the stress effect of high frequency current.

In folliculi, both large and small, the colloid is basophilic. Resorption vacuoles are scanty. Thyrocytes differ in height, being high in small folliculi and flattened - in large that is indicative of their different functional activity.

\section{Conclusions}

1. The effect of high frequency current as a dissector on the course of morphologic changes in the gland is distance-dependent, the changes corresponding to structural shock characteristics.

2. When applied directly, high frequency current causes coagulation necrosis in the thgyroid gland; in the perifocal area it results in intensified secretory response of the thyroid tissue to the extremal factor whereas in the remote area the typical structure of the nodular goitre with the signs of impaired microcirculation is evident.

\section{References:}

1. Andreas K., Tskayannis D., Linos D. (2004), Use of a diathermy systemin thyroid surgery. Arch Surg; 139: 997-1000.

2. Chaudhary I.A., Samiullah, Masood R., Mallhi A.A. (2006), Complications of thyroid surgery: a five year experience at Fauji Foundation Hospital. Rawalpindi. Pak J Surg; 22:134-7.

3. Dionigi G., Rovera F., Boni L., Castano P., Dionigi R. (2006), Surgical site infections after thyroidectomy. Surg Infect; 7 Suppl. 2: S117-20..

4. Foster R.S. Jr. (1978), Morbidity and mortality after thyroidectomy. Surg Gynecol Obstet; 146: 423-429.

5. Rosato L., Avenia N., Bernante P., De Palma M., Gulino G., Nasi P.G., Pelizzo M.R., Pezzullo L. (2004), Complications of thyroid surgery: Analysis of a multicentric study on 14.934 patients operated on Italy over 5 years. World J Surg; 28: 271-276.

6. Sadler G.P. (2006), The Thyroid glands, In: Lennard TWJ (ed). Endocrine surgery (3rd Ed). Philadelphia, PA: Elsevier Saunders; 43-78.

7. Shen W.T., Baumbusch M.A., Kebebew E., Duh Q.Y. (2005), Use of theelectrothermal vessel sealing system versus standard vessel ligation in thyroidectomy. Asian J Surg; 28: 86-9.

8. Total video-endoscopic thyroid resection via axillobilateral- breast-approach (ABBA). (2006), 10-th World Congress of Endoscopic Surgery. Berlin, 39. p. 40-41.

9. Vassilios A.L., Emmanuel P.P., Antonois A.M. et al. (2005), The use of LigaSure vessel sealing system in thyroid surgery. Otolaryngol Head Neck Surg; 132: 487-9.

10. Witzel K. (2007), The transoral access in endoscopic thyroid resection. 15th International Congress of the European Association for Endoscopic Surgery (EAESS), Athens.

Submitted: 26.04 .2015

Accepted: 21.07.2015 